\title{
Terrain Analysis using GIS for Hydrological Applications
}

\author{
Anjaly C Sunny* and K. Aswathi \\ Agricultural Engineering, KCAET (Kerala Agricultural University), Tavanur (P.O.), \\ Malappuram (Dt.), Kerala-679573, India \\ *Corresponding author
}

\section{A B S T R A C T}

\section{Ke ywords \\ Digital Terrain Analysis, Digital Elevation Model, Drainage network, ILWIS, \\ Morphometric parameters, Strahler ordering}

\section{Article Info}

Accepted:

04 March 2020

Available Online:

10 April 2020
Digital Terrain Analysis (DTA) has been conducted for analyzing the terrain of Bharathapuzha watershed to derive various geomorphometric parameters which are of importance in hydrological applications. This DTA was carried out using various operations particularly the DEM hydro-processing tool box of the Free and Open Source Software (FOSS) GIS software ILWIS. The study area was of an aerial extent of $3844.32 \mathrm{~km}^{2}$. The Digital Terrain Analysis of Bharathapuzha watershed resulted in the creation of slope map, aspect map, drainage density map, stream order map, longest flow length map, sub-catchments map, sub-watersheds of tributaries map etc. The morphometric parameters of Bharathapuzha river basin like Stream order $(\mathrm{Nu})$, Mean stream length (Lsm), Stream length ratio (Rl), Mean bifurcation ratio $(\mathrm{Rbm})$, Drainage density $(\mathrm{Dd})$, Drainage texture $(\mathrm{T})$, Stream frequency (Fs), Form factor (Ff), Length of overland flow (Lg), Relief (R), Relief ratio (Rr), Basin length, Sinuosity Index (SI) have been found.

\section{Introduction}

A knowledge on morphology and behaviour of the river is significant for appropriate planning and design of water resources projects and for having rational and scientific approach to solve different contrains. Morphology of river is the field of science that deals with the change of river plan form and cross sections due to sedimentation and erosion. The major elements to be considered for analysing the morphometry of a river basin includes, the flow dynamics and sediment transport. It plays an important role in designing, planning and maintenance of river engineering structures. Recently there has been an increasing awareness about the necessity of conducting morphological study of rivers.

\section{Digital Terrain Analysis}

The process of quantitatively describing the terrain is known as the Digital Terrain Analysis (DTA). The common synonyms are land form parameterization, geomorphologic analysis and land surface analysis. It is a digital representation of earth's topography 
(an elevation map) and is also known as Digital Elevation Model. Geomorphometric parameters, topographic attributes and morphometric variables or the general information about the terrain can be retrieved from the DEM or DTM. The term DTM refers to the set of interpolation or filtering techniques used to derive the topographic surface and the term DTA for a set of techniques used to derive the terrain parameters. The terrain analysis refers to the process employed to quantify the morphology of a terrain.

There are three important categories of digital terrain parameters namely morphometric, hydrologic and climatic parameters (Bathgate and Duram, 2003). The morphometric parameters give the detailed account of the morphology of a surface. The hydrologic parameters which are also known as the flow accumulation based terrain parameters accounts for the potential flow of materials that is erosion hazards and the climatic terrain parameters accounts for the climatic variables adjusted to the factors of relief.

In layman's terms, geomorphometry aims at extracting land surface parameters (morphometric, hydrological, climatic etc.) and objects (watersheds, stream networks, landforms etc.) using input digital land surface model (DEM) and parameterization software. For DTA, resemblance of DEM with the shapes and flow potential is more important, i. e., a good representation of shape is more important than the actual values in the DEM. This is achieved by adjusting the actual value with an additional set of filtering methods.

The parameters and objects thus extracted can then be used to improve modelling and mapping of vegetation, soils, land use, geomorphologic and geological features. Parameters or characteristics which are spatially varied can then be easily computed, stored, retrieved and analysed and secondary information can be derived.

The data handling and analysis has become much easier with the GIS tools (both software and hardware) to produce meaningful research outcomes. It has the advantage of handling attribute data in conjunction with spatial features, which was totally impossible with manual cartographic analysis. It stores both spatial and non-spatial data, layer by layer either in raster or vector format.

The linking of modelling concepts with the GIS domain is proved useful in development of a Decision Support System (DSS) and expert system based on heuristic logic (Doad et al., 2012). This tool makes the data handling job easier and meaningful. It is more versatile for analysing a large data base and large areal extent. GIS facilitates repetitive model application with considerable ease and accuracy.

Since 90's, DTA has been implemented in in many general GIS packages. DTA software like ILWIS can only run simple filter operations and derive for example the slope, aspect and hill shading maps (Ramaiah et al., 2013). The cartographic and data overlaying capability of GIS coupled with its dynamic linking ability with models plays a vital role in water management decision making process. The model output can be displayed effectively and the information stored in a particular region will be handy for use.

\section{Geographical Information System (GIS)} Software - Ilwis

ILWIS is an acronym of the Integrated Land and Water Information System. It is Geographical Information System (GIS) software with Image Processing capabilities. ILWIS has been developed by the 
International Institute for Aerospace Survey and Earth Sciences, Enschede, Netherlands and is now ILWIS Open, a Free and Open Source Software (FOSS) developed under $52^{\circ}$ North (http://52north.org).

As a GIS and Remote Sensing package, ILWIS allows inputting, managing, analysing and presenting geographical data. From the data one can generate information on the spatial and temporal patterns and processes on the earth surface.

\section{Objectives of the study}

Bharathapuzha river basin within the boundary of Kerala state has been taken for this study with following objectives:

Terrain analysis of Bharathapuzha watershed using Digital Terrain Analysis.

Extraction of the geomorphological parameters of the watershed which are important with respect to their hydrological applications.

Delineation of the watershed in to subcatchments and delineation of the watersheds of tributaries

\section{Materials and Methods}

\section{Study area}

The bharathapuzha river basin lies between $10^{\circ} 26^{\prime} 30.16^{\prime \prime}$ to $11^{\circ} 12^{\prime} 32.78^{\prime \prime}$ North latitudes and $75^{\circ} 54^{\prime} 40.74 "$ to $76^{\circ} 54^{\prime} 29.09^{\prime \prime}$ East longitudes and it covers Malappuram, Thrissur and Palakkad districts of Kerala state, India. The study area has a total drainage area of $3844.32 \mathrm{~km}^{2}$.

\section{Maps Used}

Boundary map of Bharathapuzha watershed DEM of Bharathapuzha watershed generated from Contour map

\section{Digital terrain analysis software}

ILWIS 3.31 software was used for the analysis

\section{Dem- hydro processing}

DEM parameters relevant for hydrological analysis are obtained using the DEM Hydroprocessing module in the ILWIS. The tools as given below are available in the Operationtree of the DEM Hydro-processing module in the ILWIS SOFTWARE.

\section{Dem visualization}

The DEM Visualization script creates a colour composite from a DEM. First, three shadow maps are created by the script, using three different shadow filters. The combination of them in a colour composite gives a very good impression of the relief in your area. When DEM is displayed with a special elevation representation, and then the output colour composite shadow map is added with transparency, the relief of the study area really stands out very nicely. Drainage network can also be add on top of the other layers.

\section{Flow determination}

\section{Fill sinks}

Before using the Flow Direction operation, clean-up of Digital Elevation Model (DEM) may be done, so that local depressions (sinks) are removed from DEM. The Fill sinks operation will 'remove' the following from a DEM:

Depressions that consist of a single pixel, i.e. any pixel with a smaller height value than all of its 8 neighboring pixels,

Depressions that consist of multiple pixels, i.e. any group of adjacent pixels where 
the pixels that have smaller height values than all pixels that surround such a depression.

\section{Flow direction}

In a (sink-free) Digital Elevation Model (DEM), the Flow direction operation determines into which neighbouring pixel any water in a central pixel will flow naturally. Flow direction is calculated for every central pixel of input blocks of 3 by 3 pixels, each time comparing the value of the central pixel with the value of its 8 neighbours. The output map contains flow directions as $\mathrm{N}$ (to the North), NE (to the North East), etc.

\section{Flow accumulation}

The Flow accumulation operation performs a cumulative count of the number of pixels that naturally drain into outlets. The operation can be used to find the drainage pattern of a terrain.

As input the operation uses the output map of the Flow direction operation.

The output map contains cumulative hydrologic flow values that represent the number of input pixels which contribute any water to any outlets (or sinks if these have not been removed); the outlets of the largest streams, rivers etc. will have the largest values.

\section{Flow modification}

\section{Dem optimization}

The DEM optimization operation can be used to enhance a Digital Elevation Model (DEM), on which you wish to use the Flow direction operation later on. The DEM optimization operation will 'burn' existing drainage features into your Digital Elevation Model (DEM); a subsequent Flow direction operation will thus better follow the existing drainage pattern.

\section{Topological optimization}

When a DEM and/or a flow direction map have undefined values, e.g. when there are lakes in the study area, the Topological Optimization operation can improve the results of a previous Flow direction operation and a Drainage network extraction operation to ensure a proper flow. The idea is to create one or more segment maps that will connect drainages through lake areas, so that the drainages that flow into a lake are connected to the drainages that flow out of the lake. The operation works best, when it is used several times; each time with new connecting drainages, and using the output of a first pass as input in a second pass.

\section{Network and Catchment Extraction}

\section{Drainage Network Extraction}

The Drainage Network Extraction operation extracts a basic drainage network (Boolean raster map). The output raster map will show the basic drainage as pixels with value True, while other pixels have value False. As input required is the output raster map of the Flow accumulation operation, this map contains a cumulative drainage count for each pixel.

\section{Drainage network ordering}

The Drainage network ordering operation:

Examines all drainage lines in the drainage network map, i.e. an output map from the Drainage network extraction operation,

Finds the nodes where two or more streams meet, and

Assigns a unique ID to each stream in between these nodes, as well as to the streams that only have a single node.

The output of this operation is a raster map, a segment map and an attribute table that all use a newly created ID domain. 
The attribute table contains information on each stream, such as:

Strahler ordering number, Shreve ordering number,

Stream length, calculated along the drainage, and calculated as a straight line between XY-coordinates,

Slope values in degrees and in percentages, calculated along the drainage and calculated as a straight line between $\mathrm{XY}$-coordinates, and elevation,

Sinuosity of the drainage path as a measure of meandering,

Total upstream drainage length, i.e. the total length of the streams that drain into the current one, etc.

\section{Catchment extraction}

The Catchment extraction operation constructs catchments; a catchment will be calculated for each stream found in the output map of the Drainage network ordering operation. The operation uses a Flow direction map to determine the flow path of each stream.

As input is required:

The output raster map of the Drainage network ordering operation,

The output raster map of the Flow direction operation.

As output a raster map, a polygon map and an attribute table are produced which all use the ID domain of the input Drainage network ordering map.

The attribute table contains information on each catchment, such as:

Area and perimeter of the catchment, Total upstream area, i.e. the area of all catchments that drain into this catchment, etc.

\section{Catchment merge}

The Catchment merge operation is able to merge adjacent catchments, as found by the Catchment extraction operation. In fact, new catchments will be created on the basis of the Drainage network ordering map and its attribute table.

\section{Compound parameter extraction}

\section{Overland flow length}

The Overland Flow Length operation calculates for each pixel the overland distance towards the 'nearest' drainage according to the flow paths available in the Flow Direction map.

Morphometric parameters to be calculated from the results

\section{Aspect}

The aspect of a terrain is the direction to which it faces. Aspect influences vegetation type, precipitation patterns, snow melt and wind exposure. The compass direction of the aspect was derived from the output raster data value. 0 is true north; a $90^{\circ}$ aspect is to the east, and so forth.

\section{Slope}

The slope of a terrain refers to the amount of inclination of physical feature, topographic landform to the horizontal surface. Slope analysis is an important parameter in morphometric studies. The slope elements, in turn are controlled by climato- morphogenic processes in areas having rock of varying resistance. 


\section{Stream order (u)}

Stream ordering is a widely applied method for stream classification in a river basin. Stream ordering is defined as a measure of the position of a stream in the hierarchy of tributaries. Stream number $(\mathrm{Nu})$ The stream length is measured from mouth of the river to the drainage divide near the source. Mean stream length (Lsm) Mean stream length (Lsm) reveals the characteristic size of components of a drainage network and its contributing surfaces. It has been computed by dividing the total stream length of order ' $u$ ' by the number of stream segments in the order. It is noted that Lsm of any given order is greater than that of the lower order and less than that of its next higher order in the basin. The Lsm values differ with respect to different basins, as it is directly proportional to the size and topography of the basin. Studies indicated that the Lsm is a characteristic property related to the size of drainage network and its associated surfaces.

\section{Stream length ratio $(\mathbf{R I})$}

It is the ratio between the lengths of streams in a given order to the total length of streams in the next order. The Rl values are strongly dependent on the topography and the slope.

\section{Bifurcation ratio $(\mathbf{R b})$}

Bifurcation ratio $(\mathrm{Rb})$ is defined as the ratio of the number of streams of any given order to the number of streams in the next higher order in a drainage basin and it is related to the branching pattern of a drainage network. It is a dimensionless property and shows the degree of integration prevailing between streams of various orders in a drainage basin (Magesh et al., 2013). Rb shows a small range of variation for different regions or for different environments except those where the powerful geological control dominates. Low $\mathrm{Rb}$ value indicates poor structural disturbance and the drainage patterns have not been distorted, whereas the high $\mathrm{Rb}$ value indicates high structural complexity and low permeability of the terrain.

\section{Basin length (Lb)}

The basin length $(\mathrm{Lb})$ is the longest length of the basin from the headwaters to the point of confluence.

\section{Relief (R)}

The relief $(\mathrm{R})$ is defined as the differences in elevation between the highest and the lowest points on the valley floor of a basin (Magesh et al., 2013). Basin relief is an important factor in understanding the denudational characteristics of the basin and plays a significant role in landforms development, drainage development, surface and subsurface water flow, permeability and erosional properties of the terrain. The high relief value of basin indicates the gravity of water flow, low infiltration and high runoff conditions.

\section{Relief ratio}

The relief ratio has been widely accepted as an effective measure of gradient aspect of the basin, despite uncertainties surrounding definition of its component measurements and may be unduly influence by one isolated peak within the basin. Relief ratio can be defined as the ratio of maximum relief to horizontal distance along the longest dimension of a basin parallel to the main drainage line and it measures the overall steepness of the river basin.

\section{Drainage density (Dd)}

Drainage density (Dd) is one of the important indicators of the landform element and provides a numerical measurement of landscape dissection and runoff potential. Dd 
is defined as the total stream length in a given basin to the total area of the basin (Magesh et al., 2013). Dd is related to various features of landscape dissection such as valley density, channel head source area, relief, climate and vegetation, soil and rock properties and landscape evolution processes.

A low drainage density indicates permeable sub-surface strata and has a characteristic feature of coarse drainage, which generally shows values less than 5.0. It is noted that low drainage density is favored where basin relief is low and vice versa.

\section{Stream frequency (Fs)}

Stream frequency (Fs) is defined as the ratio of the total number of stream segments of all the orders in the basin to the total area of the basin. 'Fs' is an index of the various stages of landscape evolution.

The occurrence of stream segments depends on the nature and structure of rocks, vegetation cover, nature and amount of rainfall and soil permeability.

\section{Drainage texture $(\mathrm{T})$}

Drainage texture $(\mathrm{T})$ is a product of stream frequency and drainage density. The ' $\mathrm{T}$ ' depends on underlying lithology, infiltration capacity and relief aspect of the terrain. According to Smith's classification of drainage texture, the texture value below 4 is designated as coarse; 4-10 as intermediate; above 10 as fine and above 15 as ultra-fine texture.

\section{Form factor (Ff)}

Form factor (Ff) can defined as the ratio of the basin area and square root of the basin length. Long-narrow basins have larger lengths and hence smaller form factors.

Circular basins have intermediate form factors, which are close to one. For a perfectly circular basin, the value of the form factor will be greater than 0.78 . Short-wide basins have the largest form factors.

\section{Length of overflow ( $\mathrm{Lg})$}

Length of the overland flow ( $\mathrm{Lg}$ ) is the length of water over the ground before it gets concentrated into definite stream channels. ' $L g$ ' can be defined as the mean horizontal length of flow path from the divide to the stream in a first-order basin and is a measure of stream spacing and degree of dissection and is approximately one-half the reciprocal of the drainage density.

The high $\mathrm{Lg}$ value indicates that the rainwater had to travel relatively longer distance before getting concentrated into stream channels. However, low $\mathrm{Lg}$ values indicate that the rainwater will enter the stream quickly.

\section{Sinuosity}

It refers to the curved shape of the streams.

\section{Results and Discussion}

The morphometric parameters of Bharathapuzha river basin have been examined and the results are given below. The total drainage area of the Bharathapuzha basin is $3844.320 \mathrm{~km} 2$.

The drainage pattern is dendritic in nature. Length of the largest stream was found to be $11632.20 \mathrm{~m}$ and that of smallest was $91.10 \mathrm{~m}$.

\section{Morphometric Parameters obtained are as follows:}

Slope

The degree of slope exhibited by Bharathapuzha river basin varies from $0^{\circ}$ to $70.59^{\circ}$.. The higher slope gradient in the study 
area is contributed by the hilly Western Ghats. Higher slope gradient results in rapid runoff with potential soil loss.

\section{Aspect}

The compass direction of the aspect was derived from the output raster data value. $0^{\circ}$ is true value north; a $90^{\circ}$ aspect is to the east and so forth.. The east flowing slopes mainly occur in the study area, which has a higher moisture content and lower evaporation rate and hence has high vegetation index.

\section{Drainage density}

A low drainage density indicates permeable sub surface strata and has a characteristics feature of coarse drainage, which generally shows values less than 5. The Dd of study area was obtained as $0.33 \mathrm{~km} / \mathrm{km} 2$; which indicates that study area has a weak or permeable subsurface material.

\section{Stream order (u)}

Based on the Strahler system of ordering, basin has been designated as a sixth order basin. In the study, maximum frequency is observed in the order streams. First order streams are there that do not have any tributary and there channel normally flow during wet weather.

More number of first order streams is obtained in hilly regions of study area, where points towards terrain complexity and compact nature of bed rock lithology.

The calculated result described that the total number of streams gradually decrease as the stream order increases. More number of streams indicates that the basin still undergoes erosion and the less number of streams indicates a mature topography.

\section{Stream number $(\mathrm{Nu})$}

Number of streams of different orders and the total number of streams in the basin are counted independently. Generally the number of streams gradually decreases as the stream order increase; variation in order and size of tributary basin largely depends as physiographic and structural condition of the region. High values of first order streams indicate that there is a possibility of sudden flash floods after heavy rainfall in the downstream.

\section{Stream length (Lu)}

Total length of stream segments is the maximum in first order streams and decreases with an increase in the stream order. The result reveals that the first order streams are short in length and are found in the upstream area. Streams with relatively short length are representations of areas of steep slopes and finer texture whereas longer lengths of streams are generally indicating low gradients.

\section{Mean stream length (Lsm)}

The Lsm value of study area ranges from 1.4 to $2.09 \mathrm{~km}$ with a mean value of $1.68 \mathrm{~km}$. The Lsm value differ with respect to different basins as it is proportional to the size and topography of the basins.

\section{Stream length ratio $(\mathbf{R I})$}

$\mathrm{Rl}$ value of the study area varies between values of 0.89 to 1.2. It shows an important relationship between surface flow discharge and erosional stage of the basin. It strongly depends on topography and slope.

\section{Bifurcation ratio $(\mathbf{R b})$}

The $\mathrm{Rb}$ for the study area ranges from 0.67 to 4.06. And the mean bifurcation ratio is 2.113 . The mean $\mathrm{Rb}$ characteristically ranges from 3 
to 5 for a basin when the influence of geographical structures on the drainage network is negligible. $\mathrm{Rb}$ differs for various orders, geological and lithological development of the drainage basin may be the reason for their variations.

Low $\mathrm{Rb}$ values indicate poor structural disturbances and the drainage pattern have not been distorted.

High $\mathrm{Rb}$ values indicate high structural complexity and low permeability of the terrain. Thus a low value of 2.113 indicates less structural disturbances in the basin.

\section{Basin length ( $\mathrm{Lb})$}

Bharathapuzha originates from Western Ghats at an attitude of about $110 \mathrm{~m}$ above mean sea level and drains into Arabian Sea. Lb determines shape of the basin. Study area has a Lb of $108.83 \mathrm{~km}$ which indicates an elongated basin.

\section{Relief(R)}

It is important factor in understanding the denudation characteristics of the basin. The maximum value of relief for the study area was 1459.9. This high relief value of the basin indicates the gravity of water flow, low infiltration and high runoff conditions.

Table.1 Morphometric parameters of the watershed

\begin{tabular}{|c|c|c|}
\hline SI No. & Parameters & Formula \\
\hline 1 & Stream order(Nu) & Hierarchical rank \\
\hline 2 & Stream length (Lu) & Length of the stream \\
\hline 3 & Mean stream length (Lsm) & $\mathrm{Lsm}=\mathrm{Lu} / \mathrm{Nu}$ \\
\hline 4 & Stream length ratio & $\mathrm{RL}=\mathrm{Lu} /(\mathrm{Lu}-1)$ \\
\hline 5 & Bifurcation ratio $(\mathrm{Rb})$ & $\mathrm{Rb}=\mathrm{Nu} / \mathrm{Nu}+1$ \\
\hline 6 & $\begin{array}{l}\text { Mean bifurcation ratio } \\
\text { (Rbm) }\end{array}$ & $\begin{array}{l}\mathrm{Rbm}=\text { average of bifurcation ratios of all } \\
\text { orders }\end{array}$ \\
\hline 7 & Drainage density (Dd) & $\mathrm{Dd}=\mathrm{Lu} / \mathrm{A}$ \\
\hline 8 & Drainage texture $(\mathrm{T})$ & $\mathrm{T}=\mathrm{Dd} \times \mathrm{Fs}$ \\
\hline 9 & Stream frequency (Fs) & $\mathrm{Fs}=\mathrm{Nu} / \mathrm{A}$ \\
\hline 10 & Form factor $(\mathrm{Ff})$ & $\mathrm{Ff}=\mathrm{A} / \mathrm{L}^{2}$ \\
\hline 11 & $\begin{array}{l}\text { Length of overland flow } \\
\text { (Lg) }\end{array}$ & $\mathrm{Lg}=1 / \mathrm{D} \times 2$ \\
\hline 12 & Relief(R) & $\mathrm{R}=\mathrm{H}-\mathrm{h}$ \\
\hline 13 & Relief ratio & $\mathrm{Rr}=\mathrm{R} / \mathrm{L}$ \\
\hline 14 & Relief(R) Relief ratio & \\
\hline
\end{tabular}

Table.2 Morphometric parameters of Bharathapuzha River Basin 


\begin{tabular}{|c|l|l|}
\hline Sl. No. & \multicolumn{1}{|c|}{ Parameters } & \multicolumn{1}{|c|}{ Values } \\
\hline $\mathbf{1 .}$ & Stream order(Nu) & $\mathbf{1 - 6}$ \\
\hline $\mathbf{2 .}$ & Mean stream length $(\mathrm{Lsm})$ & $\mathbf{1 . 6 8} \mathbf{~ k m}$ \\
\hline $\mathbf{3 .}$ & Stream length ratio(Rl) & $\mathbf{0 . 8 9}-\mathbf{1 . 2}$ \\
\hline $\mathbf{4 .}$ & Mean bifurcation ratio $(\mathrm{Rbm})$ & $\mathbf{2 . 1 1 3}$ \\
\hline $\mathbf{5 .}$ & Drainage density $(\mathrm{Dd})$ & $\mathbf{0 . 3 3 1} \mathbf{~ k m} / \mathbf{k m}^{\mathbf{2}}$ \\
\hline $\mathbf{6 .}$ & Drainage texture $(\mathrm{T})$ & $\mathbf{0 . 1 1 4}$ \\
\hline $\mathbf{7 .}$ & Stream frequency $(\mathrm{Fs})$ & $\mathbf{0 . 4 3 6}$ streams $/ \mathbf{k m}^{\mathbf{2}}$ \\
\hline $\mathbf{8 .}$ & Form factor $(\mathrm{Ff})$ & $\mathbf{0 . 3 6 8}$ \\
\hline $\mathbf{9 .}$ & Length of overland flow(Lg) & $\mathbf{1 . 5 1}$ \\
\hline $\mathbf{1 0}$ & Relief(R) & $\mathbf{1 4 5 9 . 9 m}$ \\
\hline $\mathbf{1 1}$ & Relief ratio(Rr) & $\mathbf{0 . 0 1 3 4}$ \\
\hline $\mathbf{1 2 .}$ & Basin length & $\mathbf{1 0 8 . 8 3} \mathbf{~ k m}$ \\
\hline $\mathbf{1 3}$ & Sinuosity Index(SI) & $\mathbf{1 . 1 5}$ \\
\hline
\end{tabular}

Fig.1 DEM Hydro-processing module in the ILWIS SOFTWARE

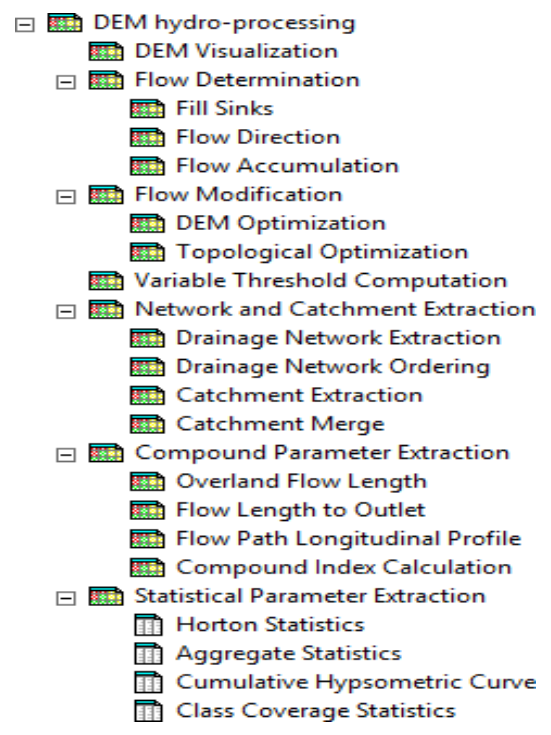

Fig.2 Digital Elevation Model (DEM)

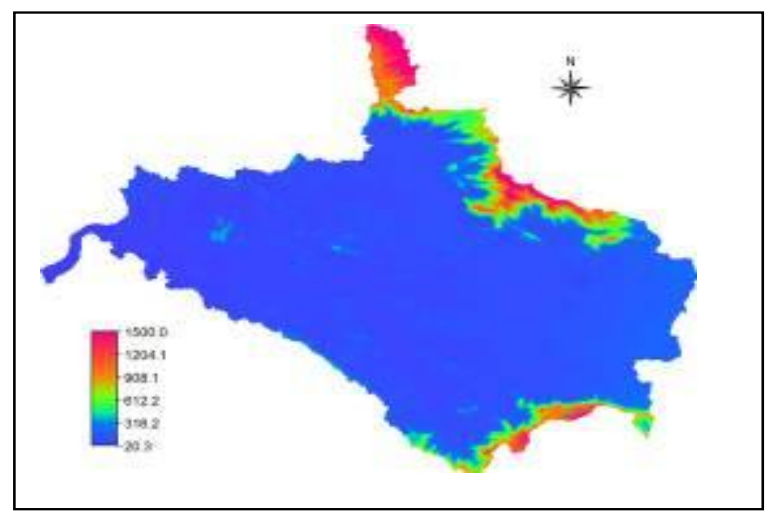


Fig.3 DEM after fill sink operation

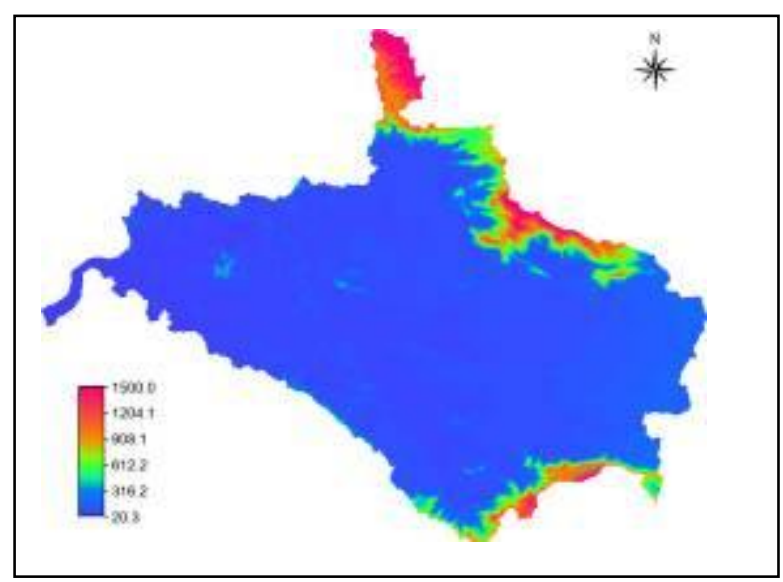

Fig.4 Difference between DEM and fill sink DEM

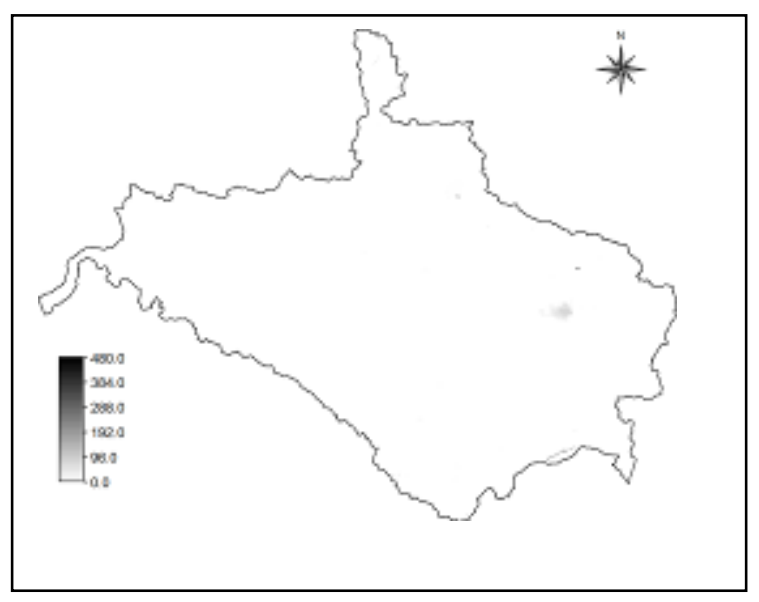

Fig.5 Flow direction map

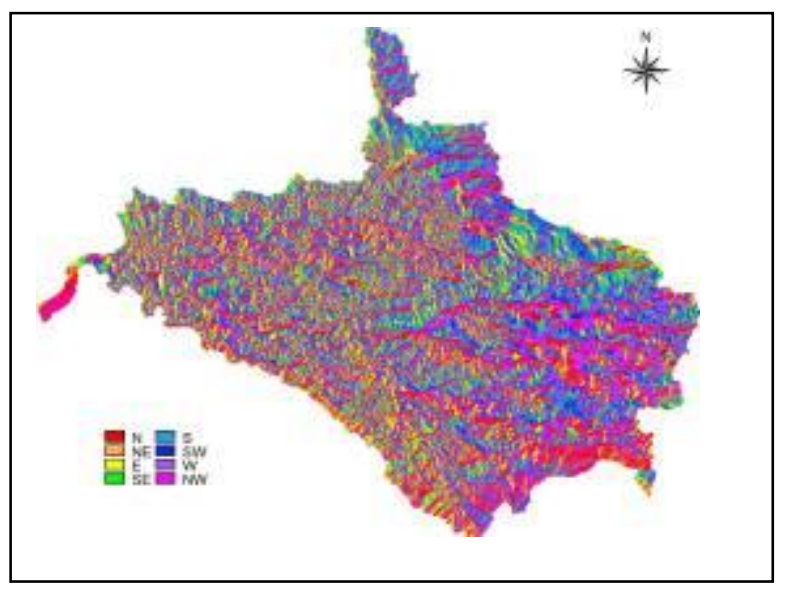


Fig.6 Extracted Sub watersheds of the tributaries

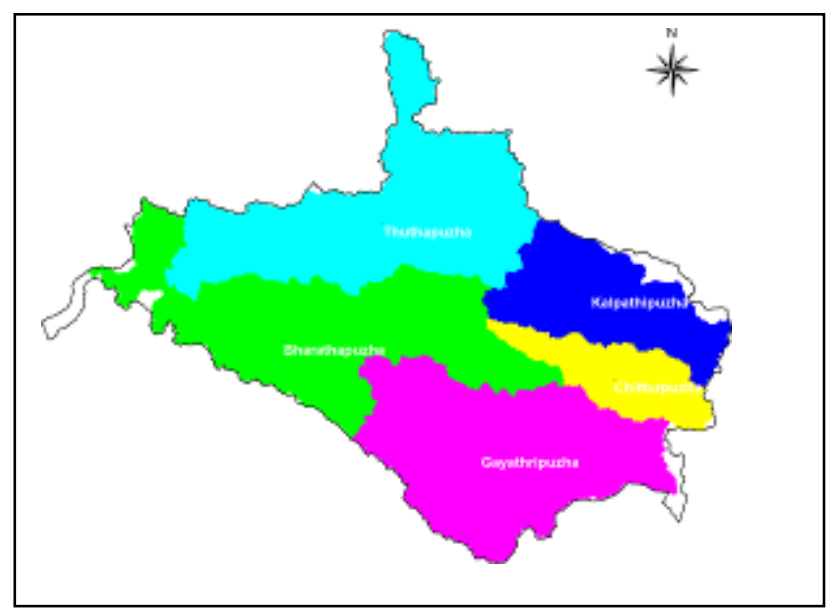

Fig.7 Wetness Index Map

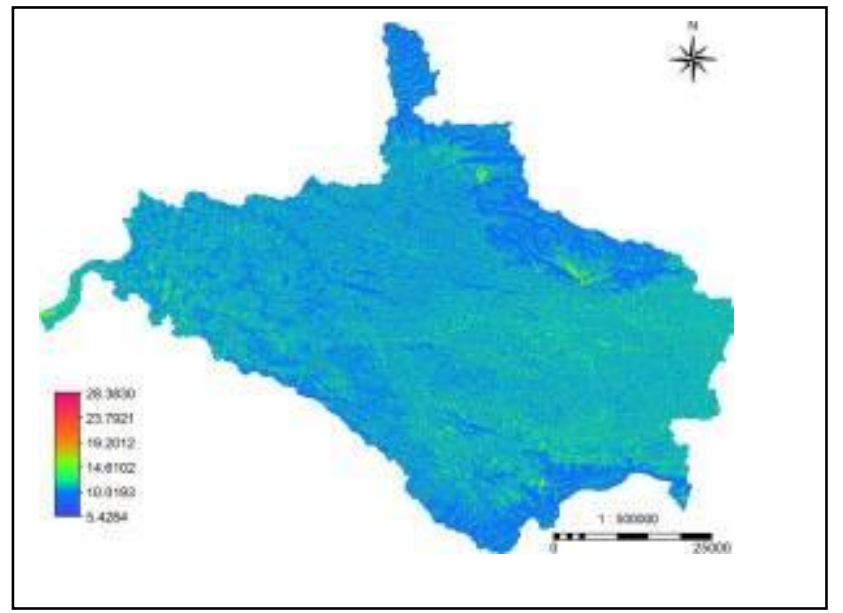

Fig.8 Slope (degrees) map

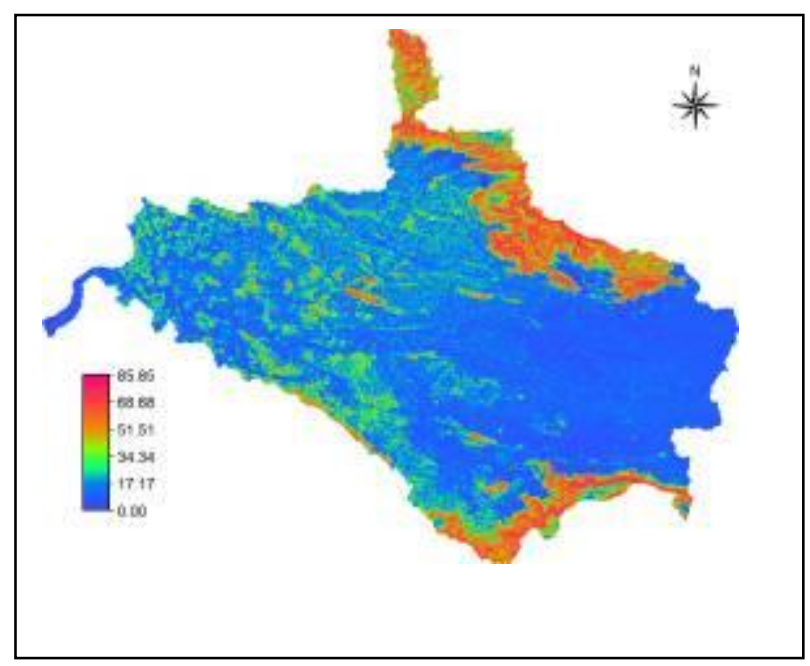


Fig.9 Overland flow length map

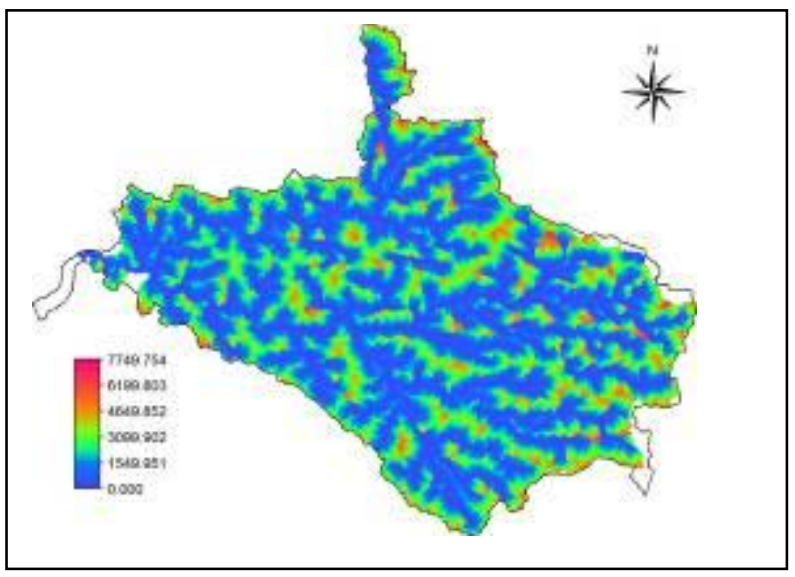

Fig.10 Stream order map

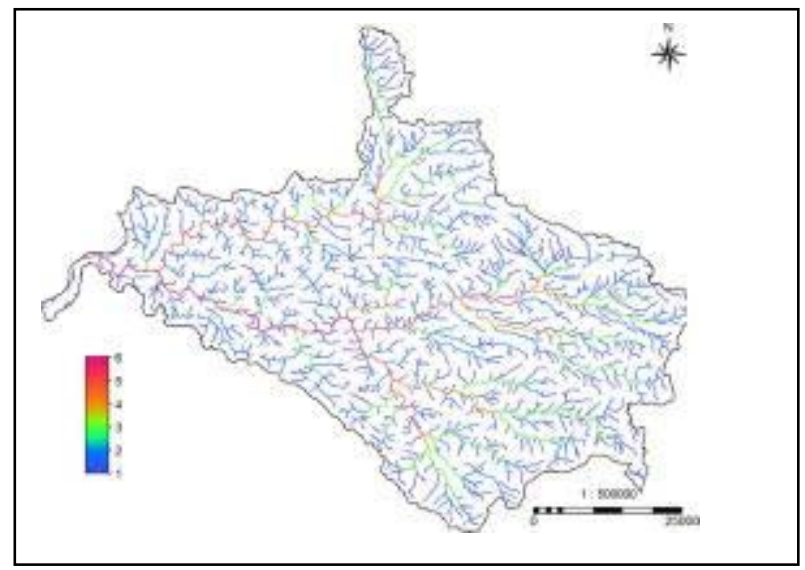

Fig.11 Aspect map

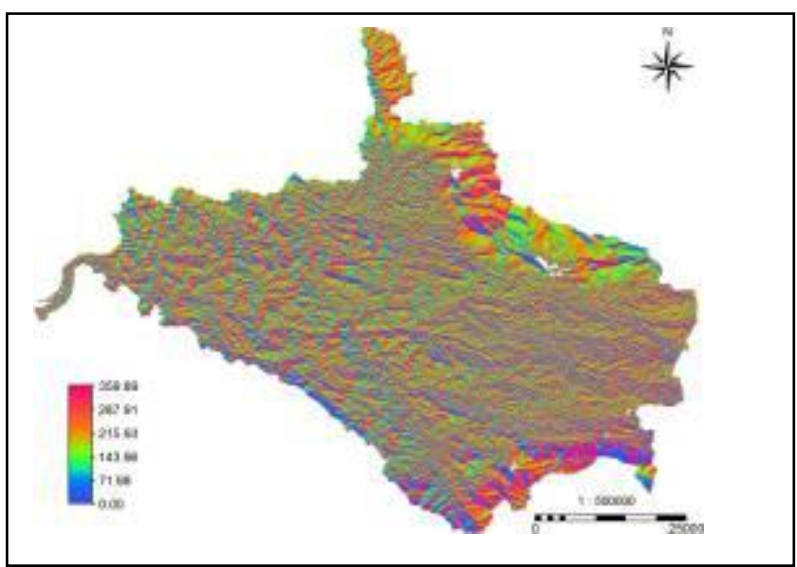

\section{Relief ratio( $(\mathbf{R})$}

The study area has got a relief ratio of 0.0134 . It indicates the extremity of erosion process operating on the slope of the basin.
Stream frequency (Fs)

The stream frequency of the study area is obtained as 0.4364 . Fs depends more or less the rainfall and the physiography of the region; 
which indicates highly permeable surface and dense vegetation.

\section{Drain texture $(\mathrm{T})$}

Drainage texture of the study area was obtained as 0.11404 . According to smith's classification of drainage texture, $\mathrm{T}$ value less than 4was designated as coarse.

The values $4-10$ as intermediate, above 10 as fine and above 15 as relief fine. The $\mathrm{T}$ value of 0.114 which is less than 4 indicates coarse texture of the soil.

\section{Form factor (Ff)}

The study area was got a form factor of 0.368 , which shows that the basin is an elongated one with lower peak flow of longer duration. For a perfectly circular basin, the value of the $\mathrm{Ff}$ value will be greater than 0.77 . Short and wide basin has the longest form factors

\section{Sinuosity index (SI)}

It refers to curved shape of the streams. For SI $<1.05$, the streams are almost straight, for $\mathrm{SI} \geq 1.05$ and $\mathrm{SI} \leq 1.25$, the streams are almost winding; $1.25 \leq \mathrm{SI}<1.50$, the streams are twisty; and basin tend to be meandering when $1.50 \leq \mathrm{SI}$. The study area has got an SI of 1.15 in average which indicates that streams are almost winding (Fig. 1-11).

In conclusion the drainage pattern is dendritic in nature. Length of the largest stream was found to be $11632.20 \mathrm{~m}$ and that of smallest was 91.10 $\mathrm{m}$. Bharathapuzha basin is an elongated basin with moderate relief and steep slope. The study area is well drained in nature with the stream order varying from 1 to 6 . The basin is dominated by lower order streams and the total length of the stream is maximum is first order streams. The Dd appears significantly lower in Bhathapuzha river basin, which is an indicator of existence of impermeable rocks and moderate relief. The quantitative analysis of linear and relief parameters using GIS is found to be of immense utility in linear basin evolution, basin prioritization for soil and water conservation and natural resource management.

\section{References}

Bathgate, J., and Duram, L. (2003). GIS based landscape classification model to enhance the soil survey.A southern Illnois case study. Journal of soil and water conservation, 119-127.

Doad, A., Warghat, S., and Khadse, S. (2012). Morphometric Analysis for Hydrological Studies using Geographical Information System: A Case Study. International Journal of Engineering Research and Technology (IJERT), 1(5), 1-8.

Magesh, N., Jitheshlal, K., Chandrasekhar, N., and Jini, K. (2013, March 15). Geographical information system-based morphometric analysis of Bharathapuzha river basin, Kerala, India. Appl. Water Sci., 3, 467-477.

Ramaiah, S., Gopalakrishna, G., Vittala, S., and Najeeb, K. (2012, December 16). Morphometric Analysis of Sub-basins in and Around Malur Taluk, Kolar District,Karnataka Using Remote Sensing and GIS Techniques. Nature Environment and Pollution Technology, $11,89-94$.

\section{How to cite this article:}

Anjaly C Sunny and Aswathi, K. 2020. Terrain Analysis using GIS for Hydrological Applications. Int.J.Curr.Microbiol.App.Sci. 9(04): 204-217. doi: https://doi.org/10.20546/ijcmas.2020.904.025 